\title{
PRIORITY RESEARCH DIRECTIONS IN THE AREA OF QUALITATIVE METHODOLOGY
}

\author{
Olga T. Melnikova, \\ Dmitry A. Khoroshilov \\ Lomonosov Moscow State University \\ Moscow
}

\begin{abstract}
The basic directions of modern theoretical and practical research in the area of qualitative methodology in Russia are discussed in the article. The complexity of research is considered from three points of view: the development of methodology of qualitative analysis, qualitative methods, and verbal and nonverbal projective techniques. The authors present an integrative model of the qualitative analysis, the research on specificity of the use of discourse-analysis method and projective techniques of expressive drawing, and also the influence of communicative competence of respondents on efficiency of focus groups. In conclusion prospects of integration of qualitative methodology are considered.

Keywords: qualitative methods, the qualitative analysis, a method of focus groups, analysis levels, objectivity, validity, reliability, interpretation, the discourse-analysis, discourse theories, a metaphor, projective techniques, expressive drawing, communicative competence, efficiency of focus group, integration, multiparadigm science.
\end{abstract}

The interest in the qualitative socio-psychological research methodology can be considered as rather traditional and well-established these days.

If in the Soviet era the Russian readership happened to be cut off from the whole complex of academic psychological discussions as well as the qualitative research tradition as such due to the known socio-historical situation, the state of affairs has changed drastically within the last twenty years.

The challenge of learning and mastering the system of qualitative methodological ideas that had been formed in the Western academic community during the last decades as well as the active application of qualitative tools in their specific practice had to be faced by Russian psy- 
chologists. Thus we had to assimilate the over more than fifty year experience of the qualitative methodology, both in theory and in practice, within a shorter period of time.

The very fact that learning aids based on the Russian authors' own research work came out at the same time as translations of classical focus-group qualitative method publications, interviews, discursive analysis, grounded theory etc, seems rather significant. That was a historical moment in the Russian qualitative research tradition taking shape to form the qualitative methodology interest of today.

Thus, the objective of the present article is to feature key research directions in the frame work of qualitative methodology that are of special interest for our science. At the same time we would like to avoid giving a false impression of our research work being comprehensive and reflecting the general state of qualitative methodology. Instead we would like to present it as a personal opinion on the qualitative research problems of today.

For further systematization of the matter we consider it logical to point out the following priority directions in the research by the authors of the present article.

1. Development of qualitative methodology and qualitative analysis like:

- elaboration of the uniform conceptual system of qualitative analysis;

- comparative study of the various methods of qualitative analysis;

- study of specific methodological features of the discursive analysis usage in psychological research reflecting the growing popularity of the method as well as the formation of a discursive psychology school.

2. Elaboration of qualitative research methods, including that of the focus-group (Melnikova, 2003; 2007). In this article we present research results on how the focus-group participants' communicative competence influences the efficacy of the group discussion and the completeness of the data received.

3. Elaboration of verbal and non-verbal projective techniques used in focus-groups and in extensive interviews such as research procedure standardization, analysis specifics and the interpretation of the received data. A procedure example and an expressive picture probe method are given below.

Let us consider each direction in detail. 


\section{Qualitative methodology and quality analysis development. Elaboration of the uniform conceptual system of quality analysis}

Elaboration of a qualitative analysis uniform model is one of our priority directions and it can be described as a level-upon-level method. It has three main features. Firstly, it specifies scientific criteria to evaluate the analytical process. Secondly, it provides a uniform reason system to compare various analytical methods. And thirdly, as an applied research tool it has a compact and practical character.

The proposed qualitative analysis method consists of the following procedure stages or data work levels:

- initial material collection,

- data definition,

- data interpretation.

Each level is examined from the point of view of:

a) its exact purpose within the framework of the whole qualitative analysis structure;

b) specific strategy of data processing;

c) specific features of the data received at that given level;

d) the problem of objectivity distortion.

Let us discuss the cited analysis levels in more detail.

Basic material level. The objective of the present level within the qualitative analysis structure is to collect primary or raw data which determines the corresponding specific strategies of the data processing. They include shorthand record or video recording, the usage of diagnostic methods and techniques and the basic strategy of observation in its broad sense, purposeful perception of the events in which progress is fixed by the researcher.

It is appropriate to present here the thesis that is of principal importance for us: the specific primary data collection strategies are closely related to those of the research objectivity rise. This thesis seems quite important in view of the following two factors. Firstly, the qualitative method criticism refers exactly to the problem of the border between the objective factors which are the recorded empirical data and their subjective evaluation. Secondly, observation as a means of qualitative material collection is considered to fully reveal the objectivity of the matter. 
Here we follow the ideas of J. Kirk and M. Miller who in the event of the data collection took the researcher's theoretical views as a guideline to concentrate on certain facts and interpret their meaning. Any suggested opinions, suppositions and attributions concerning the given events may turn out to be risky from the point of view of their objectivity (Kirk \& Miller, 1987). K. Eisenhardt also points out that the field notes make an original continuous comment on the events under observation and as such suppose some kind of interpretation (Eisenhardt, 2002). That is how different analysis levels and corresponding objectives get intersected.

The above considerations makes one include objectivity rise strategies directly into those of the primary quality data collection. We would like to highlight at least three strategies of the kind.

The first one embraces a number of practical means that could be united under a reference name of the Continuous Current Event Reflection. K. Eisenhardt proposes two such methods. Firstly, a researcher should not concentrate on the data differentiation, depending on their importance, as it is impossible to predict precisely at the level of the general material collection what data will be impotent in future. The work of their category sorting out belongs to other research stages. Secondly, it is necessary to observe closely the object of research to mark its essential changes at every level of the study. To describe the task more precisely it would be wise to ask oneself a question: "What am I studying at the moment?", "What is the difference between the present case and the previous one?" (Eisenhardt, 2002).

The second strategy is that of the Observation Standardization. There are different opinions about thus in the literature that accepts the fact that any formalized tool like, for example, a categorical observation grid offers some conceptual and analytical context. Besides, this categorical instrument can miss some essential details due to the searching nature of most qualitative research (Atkinson, 1992). D. Silverman finds continuous data collection wrong in that it makes further analysis difficult and offers a simultaneous reference to the field notes and the standardized observation plan. Transcript reference helps to reorganize and supplement categorical grids (Silverman, 2000). Apparently, the level of standardization depends on the current tasks and can change within the research process.

The third strategy to raise objectivity is part of specific primary material collection patterns and thus comes out of the very manner of the 
data received at the level that mainly looks like field notes. As a result the field notes are suggested to be sorted out divided into separate types which would differentiate at the descriptive level specific information sources, the researcher's theoretical approach, his personal ideas, opinions and impressions appearing during the course of research process. Following these rules raises the objectivity and qualitative data reliability (Kirk \& Miller, 1987).

To sum up we would like to point out once again that the data collection level appears to be basic for further analysis as well as very vulnerable to the side variables' interference. Understanding the impossibility of adequate major analysis at a higher level without the objectivity of the primary data justifies our close attention towards methodological problems arising at this point.

The level of description. The purpose at this level is the primary data summary and their structural analysis defined by the research objectives (Melnikova, 2007). As to the specific data processing strategies we chose to follow here the logics of J. Maxwell and his three strategies of the initial material structural analysis based on comments, categorizing and study of their interrelations (Maxwell, 2004).

At the first strategy stage the researcher examines transcripts, video and/or audio recordings paying attention to specific details, repeated topics and possible logical connections. A report based on the researcher's interpretation of the transcript annotations and his comments is made which Maxwell considers rather as a kind of a preparatory stage for the further work rather than an independent analysis strategy.

The second strategy named Data Coding has a larger prevalence as it translates the whole lot of unsorted data into compact structures having some special properties and logical connections. In this case coding may be considered as a kind of interpretation rather than a simple description. It should be noted that unlike Maxwell's position regarding the descriptive function of coding as its main feature, the literary sources suggest its wider interpretation including the category causality analysis.

Apparently, if the data coding is understood as a data regulation process accomplished by means of their common category separation, its function within the quality research structure turns into transformation of the collected data into a set of heuristics (Coffey \& Atkinson, 1996). Russian researcher S. Belanovsky considers the coding category search as a conceptual instrument formation process arranging the pri- 
mary data into a compact analytical generalization and creating a conceptual framework of a larger logical scope. He proposes to distinguish natural categories from the constructed ones (Belanovsky, 2001). Some foreign authors offer a similar type of classification based on picking up subsequent repetition of ideas, similar topics and theoretical constructs (Auerbach \& Silverstein, 2003). In both cases the logic of the analysis implies transition from the empirical data to some abstract notions.

It is to be regretted that the unified analysis structure is not properly described in literature on the score of the inability to bring the categorial instrument to a single model and in view of a steady fix of the research (Silverman, 2006).

The third strategy of data structure analysis is described by Maxwell as an intergroup relation study substantiating its distinction from coding on the basis of the strategy examining the categories within the integral context of the cause-and-effect relations while grouping suggests data analysis of isolated classes (Maxwell, 2004).

We have noticed that the border between coding and the causal relationship analysis can not be strictly traced, perhaps, in view of the qualitative data specificity which is their system characteristics. Besides Maxwell himself defines the third strategy rather vaguely naming "various types of a single fact study" and "some kinds of a discourse analysis" as part of it and featuring narrative analysis as a most consecutive and developed procedure (Maxwell, 2004, pp. 96-98).

So we can discuss at least two mutually complimentary types of analysis of the data intergroup cause-and-effect relationship.

The first type of the analysis can be characterized as formally logical following the main principle of the cause-and-effect relation logical analysis of intergroup matrixing and formation of semantic grids. It implies two stages: at first, categorial matrixes are examined from the structural and procedural angle within a singular study to be followed by a comparative analysis of a series of studies at the second stage (David \& Sutton, 2004; Miles \& Huberman, 1994).

The second type of analysis originates in the theory of social constructionism generally known as the narrative analysis but it does not just come to a traditional category analysis as it deals with complex psychological and linguistic constructs thus stepping up to a higher level. Unlike the formal logic strategy revealing intergroup causal relations the narrative analysis presents them as a dynamic integral structure, patterns 
the personal and social emotional event experience attired in a typeform (Burr, 2003).

The researcher carrying out a narrative analyses should be highly qualified and have a certain theoretical orientation although the above qualities are of importance during the whole stage of the data description. This remark will become clearer if we present here some analysis procedures realized at the discussed level in the broad functional aspect.

The process of coding and intergroup causal relation revelation turns out as a reduction process narrowing the primary data volume by their transformation into compact classes. The reduction as a functional method of any qualitative research means turning a raw data array into structures more convenient for the analysis. Apparently, the whole picture of the event under study can be curtailed in view of an accidental reduction of some significant data that creates the data objectivity problem at the depiction level.

High objectivity level of the general strategy of the data description lies in the analysis of how complete the event phenomenology is. In qualitative research the above strategy is known as a triangulation method assuming the correlation of the collected data and any other information (Breitmayer, Ayres, \& Knafl, 1993). The triangulation method looks quite attractive enabling researchers to get a full view of the data related to the target phenomena. But according to Silverman it is necessary to take into consideration that various information sources need different data analysis approach as correlation of a few sets of data presents a hard task dependent on the analysis structure itself (Silverman, 2006).

The level of interpretation. We have stressed above that due to the interpretation being practiced at all levels of the data analysis, it has not been allocated to any special level by many authors. At the same time acquiring this gnoseological character it becomes a fundamental principle of the qualitative methodology in general and embraces the qualitative research process at all levels (Brannen, 2004). The interpretation process starts with an empathic exposure when the researcher attempts to wear the respondent's shoes and thus get the widest data spectrum. It ends with a critical hermeneutic analysis implying determination of an underlying aspect, experience, narration unrealized by the respondent.

In fact, it seems necessary to mark out a special interpretation level aiming at shifting from the conceptually charged constructions to the 
concrete hypotheses on the subject under study to provide a received data comprehension. That is a totally different level of interpretation.

Unlike the data collection level where interpretation of the events is a side variable at this level it turns into the key analysis principle combining the received data according to the set task.

Unlike the data description level where interpretation gets a conceptualistic nature due to coding and causal effect selection, the research results are considered here as a sort of an applied aspect on the assumption of the set research objective.

According to N. Denzin one may say that the interpretation level runs the contextualisation process of the resulting data that returns the phenomenon under study back into its social context. This is the original social environment (Denzin, 2002).

The level of the data interpretation is presumably subjective so the interpretation reliability problem seems of utmost importance because of the necessity to estimate the stability of the revealed inter event connections. A critical approach towards the qualitative data analysis can be the only possible strategy on the way to solving the interpretation reliability problem.

The above model of the quality data analysis, as we have pointed out, realizes integration of various methodological strategies following rather a precise criteria that gives a chance for merging both academic and practical aspects of the qualitative research as well as for eliminating a certain methodological splinter in the area. We hope that the level-afterlevel model of the qualitative analysis will get a further development and become a subject for new discussions.

\section{Development of qualitative methodology and qualitative analysis. Comparative study of qualitative analysis methods}

The level-to-level model proposed by the authors of the present paper enables an empirical comparison of various qualitative analysis techniques on different grounds to reveal their typical advantages and drawbacks. In our research we aimed at studying modern methodology approaches used to explore qualitative data like the matrix method by Miles and Huberman, the method of grounded theory by Strauss and Corbin and the method of discursive analysis. 
Pursuant to our research target primary qualitative data in the form of an interview transcript was chosen as a research object. Keeping up the research validity we choose to examine an individual's interview result to avoid the variable of a group dynamics that under certain conditions can appear as a side effect. Altogether we have studied a hundred interviews with the total volume of 700 pages.

The examination procedure consisted of two stages. At the first stage interview transcripts were evaluated by three main qualitative analysis methods, those of matrix by Miles and Huberman (Miles \& Huberman, 1994), of grounded theory by Strauss and Corbin (Charmaz, 2006) and of discursive analysis (Potter \& Wetherell, 1987). Then a comparative analysis of these analytical approaches was carried out on the basis of the following criteria:

a) peculiarities of the primary data coding strategy;

b) peculiarities of the descriptive strategy of the received data groups;

c) peculiarities of the data interpretation strategy;

d) data group specifics as a result of the data processing by each of the above strategies;

e) aggregate result of the analysis.

Specific features of the qualitative data processing strategies under study were estimated at the second stage of our research.

The validity and reliability of the research were ensured by a special methodological series traditionally used for the qualitative analysis including methods of triangulation, of a complex data processing, a constant method as well as that of a qualitative content analysis consisting of semi-formalized procedures (Melnikova, 2007; Breitmayer, Ayres, \& Knafl, 1993; Kirk \& Miller, 1986; Silverman, 2000; 2006).

A model systematizing the above methods from the point of view of their methodological features and corresponding validity increase strategies came as the result of the research. It could be characterized as a three-step structure:

The first step is occupied by the Miles and Huberman matrix method embracing the phenomenology of the event under study within the framework of the given situation or a series of situations, with the accent made mainly upon the social characteristics of the phenomenon and the inner variables looked upon as additional. At the second step we place the grounded theory by Strauss and Corbin with gnoseological borders 
capturing some aspects of the social context seen as the result achieved by the application of the data coding strategy. At the third step there is the discursive analysis method with its methodological tools connecting the concrete material and the processes going at the macro-social level.

It is understood that the given schematic model cannot evaluate analytical approaches from the point of view of their practical value as to the qualitative research. Each has its advantages and disadvantages. The model shows the consistency demonstrated during our empirical test that also appears to be a sort of a methodological dilemma: on the one hand, the summarized information concerning large social groups risks to decrease the validity and reliability of the qualitative analysis; on the other, a particular case study often supposes application of a set of tools to verify data reliability.

The last statement has been confirmed by our experiment results. The matrix method by Miles and Huberman has, in fact, worked out a specific level to test the analysis validity, as well as corresponding techniques named contextualization procedures. The conclusions are drawn only after the test procedure. The validity is provided by a universal grid for the qualitative content-analysis and by a detailed instruction on the matrix modeling.

The grounded theory method by Strauss and Corbin has a specific feature that we have focused attention on. It implies that every stage of data processing including not only the category filling procedure but higher analysis stages as well, supposes a parallel reference to the primary non-structured material.

As to the discursive analysis method, its validity proof measures do not look comprehensive enough. Introduction of a specific analytical category such as a reference to the adoption of symbolic persons out of a large social context supposes compliance with the external validity of the analysis. But the authors of the discursive analysis method appeal to a rich philosophical tradition and suppose a complete revision of the scientific criteria character itself.

The value of the model obtained as a result of our research is that based on the empirical material it lines up epistemological characteristics of each method and concrete practical analysis strategies connected with the increase of validity and reliability. The model demonstrates correlation of epistemological and specific empirical levels in the framework of the qualitative methodology. 


\section{Development of qualitative methodology and qualitative analysis. The study of methodological specificity of the discursive analysis usage in psychological research}

We have been discussing some specific features of the discursive analysis that generally takes a significant place in psychological research creating a few methodological problems (Potter \& Wetherell, 1987) like, for example, an asymmetry in its specific application mentioned in scientific literature. The authors mark out its procedure features leaving aside its theoretical methodological aspects which made us investigate in a series of experiments these two problems occurring at the time of application of the discursive analysis in psychological research. We have defined the problems as the following questions:

1) what is gnoseological feasibility of the discursive analysis method?

2) what is the influence of explanatory constructs on the research objectivity as such?

The study of the epistemological prerequisites of the discursive analysis method is necessary to solve the above problems.

The discursive approach acts under the assumption that any cultural and social phenomena typical for the given historical moment are tests. On the one hand, the discourse is a communicative event within a certain temporary - spatial context, on the other, it is a specific practice imposed upon us by the external reality. The notion of discourse is mainly operated via the language communication structure level and it opposes the subject to the object of the communication process. The advantage of this comprehension is a clear conceptual explanation of the relationship between microsocial and macrosocial levels of communication.

These determinations suppose that the discourse structure appears to have some space for notions and interpretations while each utterance forming a discourse is to be and can be interpreted on the basis of other statements.

These notions get a special development in various discourse theories. Let us consider the following two main theories as an example (Andreeva, 2008; Arribas-Ayllon \& Walkerdine, 2008).

M. Foucault's theory supposes that the subjects of social interaction are fixed in some social position by means of a number of available lin- 
guistic practices. This statement affirms the leading role of communication or, in fact, language practice while analyzing any social phenomenon. In his further reasoning M. Foucault accentuates the interactive side of the discourse although understood in a rather one-side manner: it is proposed as an axiom that the discourse is always used to support the relationship between the power, the patterns of domination and submission, and the construction of a social I as a subject within the discourse frames at the same time constructs a definite subordination type (Potter \& Wetherell, 1987). The last supposition of M. Foucault's discourse theory has caused numerous discussions on methodology as his supposition logically leads towards the smoothing of the subject and the psyche itself. Thus the discourse becomes somewhat external in relation to the social and psychological reality, and hence methodological problems in usage of M. Foucault's discourse theory become clear (Burr, 2003).

These problems are somehow sorted out by R. Harré in his theory of discourse where it is presented as the most important part of the communicative process and the central human activity surmising reasoning and discussion of a problem. The discourse function implies systematization of social objects, attiring a status of ontological reality to them (Andreeva, 2008). The discourse is characterized as a structured sequence of intentional actions setting in motion one or another sign system and coming into being in the process of communication. The Man acts as an active user of these sign systems and a direct author of the discourse (Harré, 1996). Thus, the main difference of R. Hurrës conception from M. Foucault's theory is in the acceptance of the subject's active role in the discourse formation and in the cognition of social reality via evolution of the communicative process.

Now having defined theoretically the notion of the discourse we shall comprehend how its epistemological features are realized in the empirical reality. We have dedicated a special research to the gnoseological potentialities of the modern tools for the socio-psychological data qualitative analysis and have been successful to depict specific methodological characteristics of the discourse analysis usage and bring them into correlation with the scientific and philosophical approach to the problem.

Firstly, the text upon its analysis looks like a set of various logical connectives. The received logical constructions are individual semantic constructions examined apart from the semantic space of the text. 
Secondly, a great deal of attention is paid to the metaphors used in the information exchange as they symbolically reflect the degree of engagement of the subject under study in real experience and the subjects unconsciously determined function within some sort of a practical activity. The metaphor embraced in a single discourse if looked upon from the point of view of the analytical method under consideration unveils inner structures of the produced discourse. Thirdly, the primary data are being transformed into a special text model reflecting the text deconstruction process and its latent discourse development. It should be noted that according to our analysis the discourse behind the above models has an aloof, practically impersonal and out-of-subject nature which means that the analysis reveals a closer propinquity of the discourse analysis method to M. Foucault's conceptual constructions than to those of R. Harré, the fact rather rarely mentioned in the literature on the topic.

The discourse should not be identified with the notions of value, norms or social character revealing psychological aspects of functioning of big groups as it turns out abstract and external towards the subject and it practically always looks like a tool of social power over the individual. A cognizing subject is known for a certain passiveness of his position. The discussion discourse combines with large social practices accepted in the given society. At the same time the discourse structure becomes an unsociable self-sufficient determinant of the research participants' experience and opinions if to use philosophy language.

To sum up the discursive analysis method reveals underlying semantic aspects of the reality under study. The important proposition of the unity of the microsocial and macrosocial communication levels realized in the notion of discourse is quite debatable although accepted as an axiom by its adherents. The notion gives a possibility to extend the analysis borders from a concrete research case to much wider social entities. At the same time we have clearly demonstrated the presence of a break between the given individual's specific experience and the final models of the discursive practice in view of their peculiarities. The discursive method analysis usage demands certain prudence as its epistemological features define rather specific forms of the social reality scientific cognition. 


\section{Focus-group qualitative method development.} The study of the influence of focus-group participants' communicative competence on the group discussion effectiveness and the completeness of the received data

Due to a wide use of the focus group method for qualitative data collection purposes we have dedicated a number of practical experiments to study the variables responsible for the effectiveness of a focus group discussion and, correspondingly, for a wide range of the received quality data. A purposeful research was aimed at an empirical examination of the factor of a communicative competence of the moderator and participants of a group discussion as well as its efficacy on the whole. Moderators and participants of the focus groups were the object of the study. The methodological tools for the purpose realization included (1) a special competence model evaluating the general level of the communicative competence development and (2) a qualitative analysis of the discussion transcripts in the context of a general index of group discussion productivity.

The results of the experiment are the following:

1. We have been able to find out a significant influence of moderators with a high communicative competence level onto the discussion effectiveness at its early stage and at some problem moments. They succeed in creating a warm atmosphere, gaining the audience and carefully considering everyone's point of view. The moderators showed sincere interest in the participants' opinions, would give them an opportunity to show their worth, especially at an early stage. At the same time the moderators could not always withstand the expression of their own emotional reactions and opinions that led to a decrease in the total number of the produced ideas.

2. Three categories of group discussion participants have been sorted out from the point of their communicative competence level and their apparent influence onto the efficiency index has been traced out.

There are two to three persons in each focus group demonstrating generally high communicative competence level, trying to create an empathic atmosphere and gaining the moderator's and the group participants' favour. Often they are able to formulate the main context discussion lines, place necessary accents and summarize the other's opinions. They feel important to fully reveal their relation to and their impressions of the subject under discussion in the process of the group inter- 
personal communication but from time to time there appears a danger of suppressing other participants and, as a result, of a loss of alternative opinions.

What influence does this category of participants exert onto the focus group effectiveness? Firstly, they bring new and often creative ideas into the sum total of the generated data. Secondly, those participants who can easily establish an interpersonal communication within the group create a friendly atmosphere in it, involve others into the discussion, create a positive emotional climate, demonstrate their interest towards the interlocutor's personality that helps significantly to remove communicative barriers.

The second group of participants, about 4 to 6 in each group, has a medium communicative competence level. Most of the time they try to escape coming to the foreground and speak out occasionally. The informative part of their discourse is not great. The discussion participants of this kind would listen to the others but sometimes they would get distracted and untimely interfere with others speech to make a comment. It should be noted that during a discussion, especially at the moment of an alternative opinion clash, they would for some time stick to their point but then become silent again as if keeping aloof from the communication process.

Apparently this category makes the main focus group contingent that contributes considerably to the summary effectiveness index. They have a double influence onto the discussion efficacy: on the one hand, their personal productivity generally gets a medium index; on the other, they sometimes produce very valuable ideas that make the discussion take a turn into a new direction. Those more discreet participants seem to start noticing the audience around and start gradually exposing themselves to enter the communicative process while the more active ones quickly pick up with them to develop the new ideas.

And the last not numerous category of participants, from 1 to 3 persons in a focus group, has a low communicative competence level. Generalizing the group picture we should point out their constantly displeased mood and aggressive comments that have a destructive influence upon the group atmosphere and impeded the discussion. This kind of participants have no clear opinion and speak out in a nonconstructive and confused manner. They seem to run into extremes being either very reserved or very vocal in a dull manner with flat arguments. 
The third category of participants practically brings nothing into the common information volume. But when within the group they can be indirectly used to raise the discussion efficiency by provoking a conflict interchange making the opponents and passive participants clash to expose their positions.

Final results have demonstrated that only a few participants have a high communicative competence level while the others can be placed below the average. The first category acts a key role in the discussion and consistently assists the moderator in his specific practical function concerning the group dynamics management and the discussion context. Respondents of the other two categories are more reserved and not as effective in communication; their self-disclosure and involvement in the discussion as well as communicative barriers lifting depends considerably on the high communicative competence of the moderator and a few other participants playing him up.

The research analysis results were something of a surprise, firstly, in view of the comparative homogeneity of the group competence rating that allowed us to build the three categories described above, and, secondly, in view of a considerable difference in the participants' communicative competence levels with no intermediate steps between them. We can suggest suppose that it is the participants of high communicative competence level who are the core of the discussion.

To sum up, the featured series of experiments demonstrate that the communicative space analysis within a group discussion exposes the inner discourse mechanisms that is the very psychological continuum of the participants' interaction. The above fact gives an opportunity to work out a methodological approach to acknowledge the uniformity of the group processes and to accentuate communication as a specific environment for their realization.

\section{Development of verbal and nonverbal projective methodological devices and techniques. Expressive drawing}

Image projecting methodological devices used for profound focus group procedures and interviews are a well-known research practice to penetrate into latent mechanisms of choice and preference. Explaining his selection a respondent often names surface sensible reasons not to 
disguise his real motives but because he does not think of the true cause of his behaviour.

Direct questions do not reveal the respondents' choice of opinion, their emotions, illogical acting and unintentional reactions. That is why projective methods, and image techniques in the first place, give greater chances to comprehend motivational and emotional aspects of the respondent's perception of the examined object, his attitudes towards some social phenomenon.

Expressive drawing holds a special place among many a projective method. Its main merit is in the fact that the respondent is unable to control the process of his self-expression as compared to that of his verbal reactions while its biggest difficulty in the drawing analysis is that the researcher has to interpret the design with the help of words.

A vast number of picture characteristics and elements are examined by researchers for the interpretation purpose. For example, there has been revealed a line of regularities reflecting the respondent's attitude towards the pictured sensation: the objects causing a positive perception are often pictured in great detail and light colouring, their lines and shading quiet, thin and rounded, while lack of details, bold hand and dark colours express a negative attitude. Apart from colouring, shape, symbols and calligraphy there comes interpretation of the succession of drawing, pausing, erasing, overwhelming shading and many other parameters.

The following stages are evaluated as possible steps in the picture interpretation:

1) evaluation of "formal" features like prevalent images, colours, personages, filled space and completeness of composition;

2) marking out the object emotional characteristics on the following criteria: dynamic-static, soft-hard, smooth-rough, aggressivepeaceful, light-heavy, emotional-dull, etc. with the later evaluation of the positive and negative constituents of the general attitude towards the object.

In colour interpretation all features reflecting the picture colour palette are accounted for such as the colour preference, intensity, quantity, blending, etc. In the line interpretation the calligraphy specifics such as thickness, broadness, angularity-roundness, presence or lack of intersections is also examined. 
The picture interpretation seems complicated in view of the plurality of a possible perception of the picture elements, the latter should always follow the main tendency and reflect the general impression. That is why the correct choice of the context interpretation is of primary importance here.

The graphic methods are very special as they provide personal data as well as a variety of perceptions on the object under study which is exactly the objective of the qualitative research. Unlike them, verbal methods imply everyone's participation that results in the variety of personal opinions summing up into certain group tendencies, the personal perception being influenced by that of the group. The drawing technique procedure supposes every group member being able to express his own particular view as in the drawing a person reflects one's personal emotional state and attitude. At the same time it should be noted that the individual techniques have a negative influence upon the group dynamics as they suppress the group discussion activity. This is the reason why the design tests should be included into the group program after careful consideration.

The experience shows that the graphic projective methods provide more information about the respondents' unconscious attitudes than the verbal ones. The individual data collection increases the volume of the received information per time unit. That means that the design techniques supply a lot of information for a short time period but it is necessary to have some time left to discuss the drawings.

There is another specific feature for using pictures in the qualitative research. It often happens that the respondents have difficulty in expressing in words their attitude towards the object under examination. A respondent may use a couple of insignificant remarks in an attempt to describe the nuances of his perception while a drawing or a design becomes a provocative factor that excites imagination and brings words. Thus graphic methods ease and stimulate the opinion voicing process and help to find finer aspects of the group participants' view onto the object under examination.

The graphic projective methods help to express the deepest subconscious notions that not always coincide with the verbal component, and that is yet another peculiarity of the model. It can happen that the graphic technique results contradict verbal characteristics or sometimes they can explain and extend them, but in both cases the respondents' comments can be used for the picture interpretation. 
The interpretation subjectivity often mentioned in connection to the graphic projective method should be compensated for to escape the limitation of drawing techniques and that highly depends on the researcher's experience. Another way of diminishing the subjectivity influence is that of comparison of the data with the information received by means of other techniques as well as with the respondents' opinion on their own pictures.

Projection methods are irreplaceable as they expose the level of irrational ideas, illogical behaviour and unconscious attitudes when the respondent projects himself onto the creation of his own fantasy. His train of thought is a key to understanding of his feelings both on the intuitive and subconscious levels.

The psychological drawing method is very simple. The participants are offered to express their feelings about the object or phenomenon under discussion by making its picture. Everyone gets a clean sheet of paper and a set of coloured pencils or crayons. They have not more that three minutes to do the task and write three words featuring their sensation about the picture. Later the respondents make comments on their drawings to explain what they had been trying to express.

Before starting the task it seems appropriate to have a little warmup, for example, to offer the group to portray the feelings of anger and peacefulness. The advantages of the attempt are obvious: firstly, depicting a simple emotional state cannot be very difficult, so the respondents can see that they are able to cope with the task and express the emotion as a picture, and secondly, their training sketches can be a useful background information if complications arouse with the interpretation of non-trivial "creative solutions."

After the drawing session is over there are two ways to get additional information from the respondents.

1. The simplest way is when the moderator asks everyone in turn to show his drawing and explains its meaning while the rest take part in the discussion and with their comments stimulate the author to say what the image is about and what his feelings are. It is important that every participant explains all the essential details of the picture as well as how they correspond to the topic under discussion although that would not mean that the moderator has got a ready-made interpretation of the picture.

2. The other approach is to ask the respondents to comment the drawings of the other participants with the author of the picture remark- 
ing on the true and wrong comments. This allows involvement of the whole group in an attempt to analyze the image and, thus, the subject of the examination. But quite often this procedure can be quite time consuming while the obtained information comes out as useless if the participants find it difficult to interpret their drawings or some "artists" are not ready to reveal their sincere feelings, especially if their opinion differs from that of the others. Some respondents grow very reserved in the situation when they are suggested to express themselves with the whole of the group's attention attached to them, and they are unable to give out any useful information.

It is worth noting that one can always find features about the picture offering some sort of a hint or prompting for its interpretation such as the following examples: proximity-distance, activeness-passiveness, anxiety-calmness, tidiness-untidiness. In such a case the moderator can make an attempt to softly ask the respondent if his subject vision coincides with the other's interpretation but the moderator should by no means play the part of a psychiatrist.

Verbal characteristics play a significant part in the picture analysis as the respondents can, for example, comment on their personal colour perception in their pictures. If a participant is asked to explain the use of the black colour telling his perception of an ideal tea he can comment the colour as nice, tasty, classical while another would say that the blue colour used to depict tea is associated with the "blue blood."

With the involvement of the respondents in the discussion their attitude towards the discussed subject becomes more lucid as they carry on unfolding a specific associative line, the moderator stirring up the talk. The above example of the colour chosen to express one's perception of the tea leads to the conclusion that they are not discussing the tea any more but the desirable state of mood that they can get with it. The respondents' comments help a lot to comprehend their own attitude towards the object under examination.

The process of interpretation in general is a transition of the received image into a metaphorical description of the examined object, the metaphors being translated into the professional psychological language. The main difficulty here is the plurality of the possible versions as the interpretation of various details should submit to the general perception, the main tendency. The choice of the right context for the interpretation is of utmost importance. There have been made numerous attempts to sort 
out the most significant components of the graphic production under research during the last few years.

The sensation analysis is part of interpretational modes of working with the graphic space such as, steadiness-unsteadiness, etc. The interpretation should start with the general impression from the drawing like the emotional tone experience and the completeness of the information within its context. That is an intuitive empathic process that comes with the researcher's experience. The psychotechnique of acquiring the image is the ability to let the first impression enter one's consciousness without the participation of the intellect as it is the support of the general impression that often allows to get rid of the plurality of a single sign. The analyst needs developing his ability to get deep into the graphic to introspect the emotions caused by it. It is also important that speech metaphors should be related to the graphic image.

It is not advised to break the picture into concrete elements to interpret each part of it separately as at the moment of drawing the sheet of paper is perceived by the drawing person as "a field" for his activity where each symbol starts "playing" only in the context with the other symbols and the field itself. The notion of separate symbols should be taken into account but the most important thing is to catch the general notion of the picture. True, another problem can appear at this stage as the interpreter's expectations and his emotional state can influence his perception, so it is recommended to apply the given pattern together with the others.

The relationship between the group members and that of the moderator and the respondent makes a significant impact on the research result. The interaction of the group participants and their reciprocal action with the researcher may lead to the fact that the participants' comments stop being independent and that considerably complicates the result analysis.

Polemicising with the concern often expressed about the influence of the researcher's personality onto the eventual result we are developing the ideas of Gordon and Langmaid of the impossibility to extract the researcher out of the situation under examination and that the moderator can and shall influence the result, the positive influence being provided exclusively by his qualification, professionalism and perspicacity. Gordon and Langmaid positively state that subjectivity is an integral part of the qualitative process like knowledge and experience of the qualitative 
researcher are the basis of his "subjectivity" (Gordon \& Langmaid, 1988, p. 146). The moderator's positive influence should reveal in the respondents' level of openness, in his stimulation of the result insight and never impact their content.

It is important to understand that some respondents can read the notion of symbols differently from the commonly accepted interpretation and that is the reason why they are asked to picture their dramatic emotional state of both positive and negative nature. That gives a chance to correlate the interpretation to follow in accordance with the subjective deviations of the symbol interpretation norm.

The analysis of the verbal components and their interrelations with the symbolic forms enriches significantly the interpretation. The verbal component supplement is an important step in revealing the attitude towards the subject or phenomenon under discussion because during drawing censor instances relax and the words describing the picture fully reveal the unconscious verbal reaction to the subject or phenomenon in view.

At the time of analysis it is important to pay attention to the fact that any components of the respondent's changing "personal world" can appear as symbols in the picture. Among the most likely components there can be: settings around the task being carried out; attitude to the group; "respondent-moderator" relationship; state of health; mood, psychological state; unsolved problems; objective and subjective need in the given product.

The analysis of all the interpretation lines can give a dimensioned sketch of the perception demonstrating the respondent's emotional attitude towards the object under study. Some interpretation models practice analysis of pauses, erasure, excessive shading and image inconsistency as the emotion indicator as the drawing process gets broken at the places connected with emotional experience. This approach is based on the facts exposing emotional experience influence on the course of psychic processes as in the case of thick and thin lines in the drawing: it has been demonstrated that the line thickness is correlated with the respondent's anxiety level.

Soft round lines and stiff, straight, especially scrappy, thick and angular hand reflect different feelings. Soft round lines speak of a more favourable state, of a higher emotional stability, balance, harmony while straight lines show tension, inner protest and more negative emotions. 
Combination of the line character and the chosen colouring is of great importance in interpretation.

There has been made a number of attempts recently in the research of the social object perception to standardize the interpretation of the results of the expressive graph method, particularly marking out the graphic and intuitive (ground) components like the following:

Colour. The number of the used colours, brightness or dullness, colour combinations. As a rule this category reveals the emotional component of the image.

Composition. The composition means correlation of the graph separate elements, the graph structure. Disposition of the elements on the paper, symmetry or its absence, the presence of a background, the integrity, dynamics or statics, orientation and centrality - all that is of significance for this category. Composition peculiarities reflect the structure properties of the social object image, in other words, its pattern, balance, conflictness or harmony.

Form. The form can be angular or round, light or heavy. Its completeness and repetition of details areas as well meaningful. This category reveals the cognitive component of the image transferring the features of the object itself.

Lines. This category describes the type of the lines positioning (unidirectional or differently directed), soft or thick hand, presence or absence of shading, detailed subtleness of the image.

Size. The big or small size may reflect, for example, the significance of the object for the respondent. Line the lines, the image size may reveal the motivation characteristics of the subject perception like the interest in the object.

Subject matter (abstract / concrete). This category considers the presence of object-specific components or images. They can be divided into symbolic images of the conventional connotation like, for example, the arrow-pierced heart, and the original (individual) images. The presence of the first or the latter makes a difference in the interpretation. The category, in general, exposes the image implication or sentiment component marking out the sense of the personality transformed into the image.

The density of paper filling. Big size graphs are sometimes only outlined that suggests that the degree of the paper shading or colouring can give out the image perception motivation. 
As we suppose that some special features of the expressive design reflect the individual peculiarities of the subject perception, it is important to separate typical graph characteristics revealing the respondent's personal specifics from those of the social object imaging. There exists on equal grounds the two realities within a expressive drawing: that of the individual projection of the perception subject and that of the social cognition of the perception subject. For convenience we can sort out the graph categories specific for the reflection of various aspects of the social object perception ("composition," "subject matter"), and the categories specific for the exposure of the respondent's individual nature ("lines").

Specific graph features are typical of the expression of some or other aspects of the social object perception.

The Composition reflects the features of the social object image structure like pattern, balance, conflictness or harmony.

The Forms used in the graph reveal the cognitive component of the image transferring the features of the object itself like liveliness, dynamics.

The Colour is universal to express various, mainly emotional characteristics of the image. The emotional evaluation as an image component is determinant for the picture interpretation because the presence and nature of work of the majority of the picture elements highly depend on the author's personal attitude towards it, that is if he likes or does not like the object he is portraying.

The Detail Density in the picture reveals the motivation component, and it does not much depend on the respondent's individual characteristics.

This analysis structure may be most useful for a better interpretation of such a complicated non-structural object like a picture. But the expressive drawing method being on the border of science and art exposes the underlying layers of human psych by means of imaging. It should always be kept in mind that there is no and there cannot be a monosemantic interpretation of the image components, no matter how attractive the idea of creating such a regularity could be.

The decisive factor is the interpreter's ability to get the feel of the picture, grasp the feeling of its completeness and comprehend the total scope of the responder's experience and of the factors that have influenced the resulting effect. 


\section{Conclusion}

The above mentioned directions of our research clearly demonstrate the necessity of integration of various traditions and theoretical systems of the qualitative analysis. The problem of standardization and reduction of the qualitative analysis procedure to a few general models and criteria is becoming quite pressing in the psychological science. It is obvious that such a model should combine the data collection stage and the following stages of systematization and interpretation of the collected data. The thick handbooks systematizing the problems of the qualitative analysis which have appeared within the last decade are a sure proof of the tendency pointed out in the present paper. At the same time we would like to mention the fact of historical significance that psychological science has not been able to produce a united methodological paradigm and has been acknowledged a multiparadigm science (Kornilova, 2009). The multiparadigm nature of the science suggests a free and equal co-existence of various research traditions revealing different aspects of the subject under examination. This opinion seems true for the present situation in the qualitative methodology: simultaneous development of various approaches based on differing methodological components, first of all, indicates the actuality and progress of this research area. It means there goes the formation of a new uniform system of interaction approach, combining scientific and vision structures and suggesting a certain degree of creative freedom of the analysis.

We hope that our work is but another step on the way towards the integration of the qualitative methodology and that it will attract the attention of future researchers.

\section{References}

Andreeva, G.M. (2008). Problema âzyka v social'noj psihologii [Language Problem in Social Psychology]. In T.V. Akhutina \& D.A. Leontiev (Eds.), Psihologiâ, lingvistika i meždisciplinarnye svâzi: sbornik naučnyh rabot $k$ 70-letiû so dnâ roždeniâ Alekseâa Alekseeviča Leonteva [Psychology, Linguistics and Interdisciplinary Connections: Collection of Research Publications Dedicated to the $70^{\text {th }}$ Birthday Anniversary of Alexey A. Leontiev] (pp. 138-188). Moscow: Smysl.

Arribas-Ayllon, M., \& Walkerdine, V. (2008). Foucauldian Discourse Analysis. In W. Stainton-Rogers \& C. Willig (Eds.), Handbook of Qualitative Research in Psychology (pp. 91-108). London: Sage. 
Atkinson, P. (1992). Understanding Ethnographic Texts. Thousand Oaks, CA: Sage.

Auerbach, C.F., \& Silverstein, L.B. (2003). Qualitative Data: an Introduction to Coding and Analysis. New York: New York University Press.

Belanovsky, S.A. (2001). Metod fokus-grupp [Focus Group Method]. Moscow: Nikollo-M.

Brannen, J. (2004). Working Qualitatively and Quantitatively. In C. Seale, G. Gobo, J. Gubrium, \& D. Silverman (Eds.), Qualitative Research Practice (pp. 312-326). London: Sage.

Breitmayer, B.J., Ayres, L., \& Knafl, K.A. (1993). Triangulation in Qualitative Research: Evaluation of Completeness and Confirmation Purposes. Image: Journal of Nursing Scholarship, 25 (3), 237-243.

Brockmeier, J., \& Harré, R. (2000). Narrativ: problemy i obeŝaniâ odnoj al'ternativnoj paradigmy [Narrative: Problems and Promises of One Alternative Paradigm]. Voprosy filosofi, 3, 29-42.

Burr, V. (2003). Social Constructionism. London, New York: Routledge.

Charmaz, K. (2006). Constructing Grounded Theory: A Practical Guide through Qualitative Analysis. London: Sage.

Coffey, A., \& Atkinson, P. (1996). Making Sense of Qualitative Data. Thousand Oaks, CA: Sage.

David, M., \& Sutton, C.D. (2004). Social Research: The Basics. London: Sage.

Denzin, N.K. (2002). The Interpretive Process. In A.M. Huberman \& M.B. Miles (Eds.), The Qualitative Researcher's Companion (pp. 349-366). London: Sage.

Eisenhardt, K.M. (2002). Building Theories from Case Study Research. In A.M.Huberman \& M.B. Miles (Eds.), The Qualitative Researcher's Companion (pp. 5-36). London: Sage.

Gordon, W., \& Langmaid, R. (1988). Qualitative Market Research. A Practitioner's and Buyer's Guide. Aldershot: Gower.

Harré, R. (1996). Vtoraâ kognitivnaâ revolûciâ [Second Cognitive Revolution]. Psihologičeskij žurnal, 2, 3-15.

Kirk, J., \& Miller, M.L. (1986). Reliability and Validity in Qualitative Research: Qualitative Research Methods. Newbury Park: Sage.

Kornilova, T.V. (2009). Označaet li svobodnaâ konkurenciâ idej otkaz ot kriteriev naučnosti v psihologii? [Does Free Competence of Ideas Mean Refusal of the Scientific Criteria in Psychology?]. In A.L. Zhuravlev, T.D. Martsinkovskaya, \& A.V. Yurevich (Eds.), Progress $v$ psihologii: kriterii $i$ priznaki [Progress in Psychology: Criteria and Signs] (pp. 111-125). Moscow: IP RAN.

Larkin, M., Watts, S., \& Clifton, E. (2006). Giving Voice and Making Sense in Interpretative Phenomenological Analysis. Qualitative Research in Psychology, 3 (2), 102-120. 
Lewis-Beck, M.S., Bryman, A., \& Liao, T.F. (2004). The Sage Encyclopedia of Social Science Research Methods. Thousand Oakes, CA: Sage.

Maxwell, J.A. (2004). Qualitative Research Design: An Interactive Approach. Thousand Oaks, CA: Sage.

Melnikova, O.T. (2003). Fokus-gruppy v marketingovom issledovanii: Metodologiâ i tehniki kačestvennyh issledovanij v social'noj psihologii [Focus Groups in a Marketing: Qualitative Technique Methodology and Techniques in Social Psychology]. Moscow: Akademiâ.

Melnikova, O.T. (2007). Fokus-gruppy: metody, metodologiâ, moderirovanie [Focus Groups: Methods, Methodology, Moderating]. Moscow: Aspekt-press.

Miles, M.B., \& Huberman, A.M. (1994). Qualitative Data Analysis. Thousand Oaks, CA: Sage.

Potter, J., \& Wetherell, M. (1987). Discourse and Social Psychology: Beyond Attitudes and Behavior. London: Sage.

Richards, L. (2005). Handling Qualitative Data: A Practical Guide. London: Sage.

Salner, M. (1989). Validity in Human Science Research. In S. Kvale (Ed.), Issues of Validity in Qualitative Research (pp. 47-92). Lund: Studentlitteratur.

Silverman, D. (2000). Doing Qualitative Research: A Practical Handbook. London: Sage.

Silverman, D. (2006). Interpreting Qualitative Data: Methods for Analyzing Talk, Text and Interaction. London: Sage.

Strauss, A., \& Corbin, J. (1990). Basics of Qualitative Research. Grounded Theory. Procedures and Techniques. London: Sage. 